\title{
Total Syntheses of Mycolactone A/B and its Analogues for the Exploration of the Biology of Buruli Ulcer
}

\author{
Sarah Saint-Auret, Anne-Caroline Chany, Virginie Casarotto, Cédric Tresse, Lise Parmentier, \\ Hajer Abdelkafi, and Nicolas Blanchard*
}

Dedicated to Prof. Yoshito Kishi on the occasion of his 80th birthday

\begin{abstract}
Buruli ulcer, classified as a neglected tropical disease by the World Health Organization, is caused by a mycobacterium which secretes a macrolidic exotoxin called mycolactone $A / B$. In this article, several synthetic strategies for the preparation of this toxin are discussed, highlighting the importance of total synthesis for the exploration of biological mechanism underpinning relevant human diseases.
\end{abstract}

Keywords: Buruli ulcer · Diverted Total Synthesis · Mycolactone · Total Synthesis

\section{Introduction}

Among the human mycobacterial infections, Buruli ulcer holds a special place. ${ }^{[1-3]}$ This necrotic skin disease was first clinically reported in 1948 by Australian researchers from the Pathology Departments of the Melbourne University and Alfred Hospital, Melbourne, ${ }^{[4]}$ although previous informal reports could be traced back to previous centuries. [1] Classified as a neglected tropical disease by the World Health Organization, this disease is caused by the environmental Mycobacterium ulcerans and affected nearly 2'000 new patients in 2016, $90 \%$ of whom live on the African continent. Of particular interest is the un-

${ }^{\star}$ Correspondence: Dr. N. Blanchard Université de Strasbourg

CNRS, Laboratoire de Chimie Moléculaire UMR 7509 67000 Strasbourg, France

E-mail: n.blanchard@unistra.fr usual biology associated with Buruli ulcer, combining major tissue necrosis, local analgesia and defective inflammation. ${ }^{[5-8]}$ From a molecular point of view, it was discovered in 1999 that M. ulcerans secretes an exotoxin called mycolactone $\mathrm{A} / \mathrm{B}$ that is responsible for all the biological effects observed in Buruli ulcer. ${ }^{[9]}$ This major breakthrough triggered intense efforts from various scientific communities during the past two decades with the goal of synthesizing mycolactone and understanding how such a small molecule can mediate these effects. Indeed, from a fundamental perspective, the study of the functional interactions of mycolactone $\mathrm{A} / \mathrm{B}$ is essential to grasp the different biological mechanisms, especially of the mycolactone A/B-induced immunosuppressive effect. Synthetic chemistry is an important element in this endeavor since it allows preparation of analytically pure mycolactone A/B and also grants access to designed analogues that could act as specific probes in a given biological context. For the past ten years, we have been working in close collaboration with the Immunobiology of Infection Group from the Department of Immunology of the Pasteur Institute in Paris. ${ }^{6,7]}$ The aims of this joint research effort are to decipher the mechanisms by which mycolactone deviates biological mechanisms and to explore the therapeutic potential of this macrolide against inflammatory pain.

Herein, we highlight the key achievements of the different synthetic strategies for the total synthesis of mycolactone A/B and its analogues. An in-depth discussion of the chemistry and biology goes beyond the scope of this article, and can be found in research articles ${ }^{[10-15]}$ and reviews. ${ }^{[1,2]}$

\section{Results and Discussion}

Mycolactone is composed of three different sectors: a 12-membered macrolactone $\mathrm{C}(1)-\mathrm{C}(11)$, a northern $\mathrm{C}(12)-\mathrm{C}(20)$ fragment, and a southern $\mathrm{C}\left(1^{\prime}\right)-\mathrm{C}\left(16^{\prime}\right)$ fragment, the latter being composed of different geometrical isomers in dynamic equilibrium (Scheme 1). For the sake of simplicity, we will refer here only to the two major isomers of the $\mathrm{C}\left(4^{\prime}\right)-\mathrm{C}\left(5^{\prime}\right)$ sector, namely the $Z$-isomer (mycolactone $\mathrm{A}, 60 \%$ ) and the $E$-isomer (mycolactone B, 40\%).

Following the pioneering work of Kishi ${ }^{[16]}$ that established the stereostructure of mycolactone and proposed elegant and efficient syntheses of mycolactone $\mathrm{A} / \mathrm{B},{ }^{[17]}$ several research groups have reported total and partial syntheses of mycolactone. A classic and logical disconnection adopted by Kishi,[16] Negishi,[18] Altman $^{[19]}$ and Aggarwal[20] is the formation of the ester function at $\mathrm{C}(5)$, between a protected $\mathrm{C}(1)-\mathrm{C}(20)$ fragment and the $\mathrm{C}\left(1^{\prime}\right)-\mathrm{C}\left(16^{\prime}\right)$ southern sector. We hypothesized that the $C(13)-C(14) \sigma$-bond of the macrolactonic fragment $\mathbf{1}$ could be elaborated through a palladium-catalyzed Suzuki cross coupling and that the trisubstituted $\mathrm{C}(8)-\mathrm{C}(9)$ double bond could arise from either a ring-closing metathesis (Strategy 1) or a palladium-catalyzed bromo-allylation reaction of an alkyne (Strategy 2). On the other hand, the synthesis of the southern fragment $\mathbf{2}$ of mycolactone A/B was proposed to rely on two key steps, a palladium(0)-catalyzed and copper(I)-mediated Stille cross-coupling for the formation of the $\mathrm{C}\left(7^{\prime}\right)-\mathrm{C}\left(8^{\prime}\right)$ $\sigma$-bond as well as osmium-catalyzed asymmetric dihydroxylation reactions 
for the control of the $\mathrm{C}\left(12^{\prime}\right)-, \mathrm{C}\left(13^{\prime}\right)$ - and $\mathrm{C}\left(15^{\prime}\right)$-stereogenic centers.

\section{Synthesis of the C(1)-C(20) Fragment of Mycolactone A/B by a Ring-closing Metathesis Strategy}

In a first approach towards the $\mathrm{C}(1)-\mathrm{C}(20)$ fragment of the exotoxin of $M$. ulcerans, a ring-closing metathesis (RCM) strategy was explored for the elaboration of the 12-membered macrolactone from simple precursors (Scheme 2). [21]

The Brown asymmetric allylation reactions of aldehyde 3 led to 4-syn or 4-anti with excellent diastereoselectivities and good yields on multigram scale. The homoallylic alcohol 4-syn was then transformed into the heptanoic acid derivative 5 in four steps. The substitution of the $\mathrm{C}(8)$-iodine atom by a vinyl nucleophile in the presence of the C1-carboxylic acid turned out to be quite problematic and it was found after careful optimization that the Cossy vinylation [22] using a Grignard and a catalytic amount of $\mathrm{Fe}$ (III) was the only method leading cleanly to $\mathbf{6 a , b}$ in moderate to very good yields. The latter were esterified with 4-anti thus delivering the RCM precursors $\mathbf{7 a}, \mathbf{b}$.

Although RCM is an established strategy for the preparation of macrolactones of various sizes, it should be noted here that only a handful of precedents were reported for the construction of 12-membered macrolactone, almost all being pre-organized systems based on a 1,2-disubstituted aromatic ring. Indeed, studies of the RCM strategy from 7a,b revealed many subtleties. The RCM of $7 \mathbf{a}$ proceeded uneventfully with different metathesis pre-catalysts, delivering 8a in $92 \%$ as a single $E$-isomer when using Grubbs second-generation pre-catalyst [Ru]-2 (Scheme 3, box A1), the structure of which being proved by an X-ray diffraction study of an advanced intermediate. It should be emphasized here that $\mathbf{8 a}$ does not meet

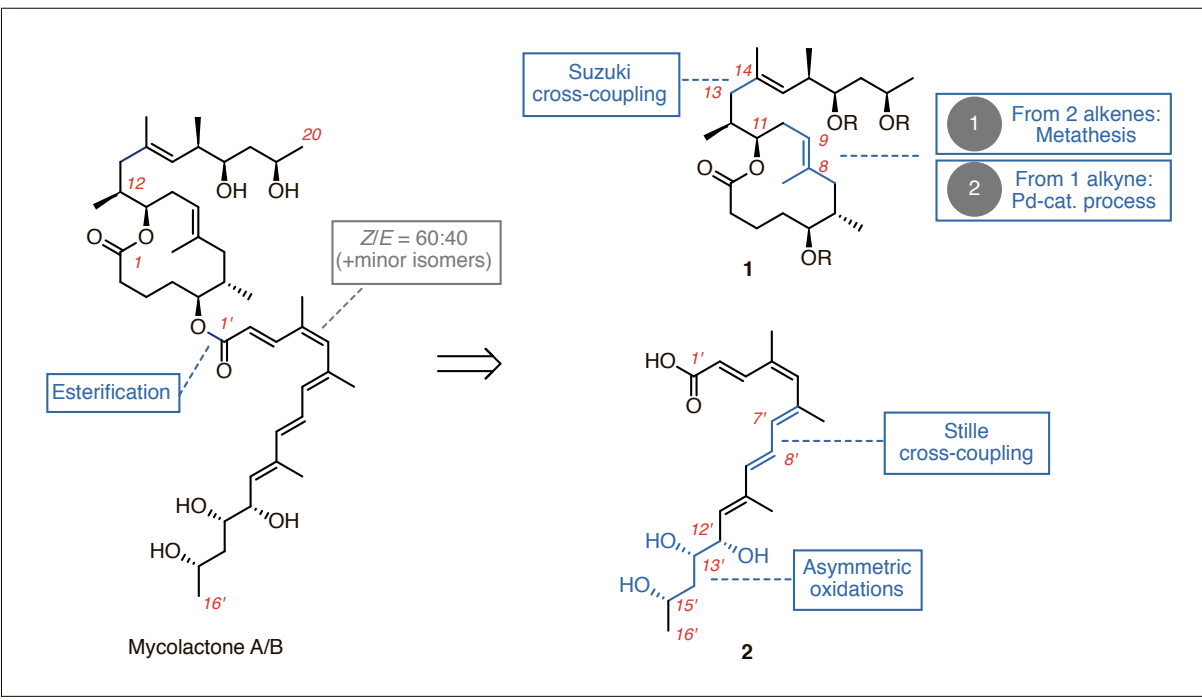

Scheme 1. Mycolactone A/B and proposed key steps of its total synthesis.

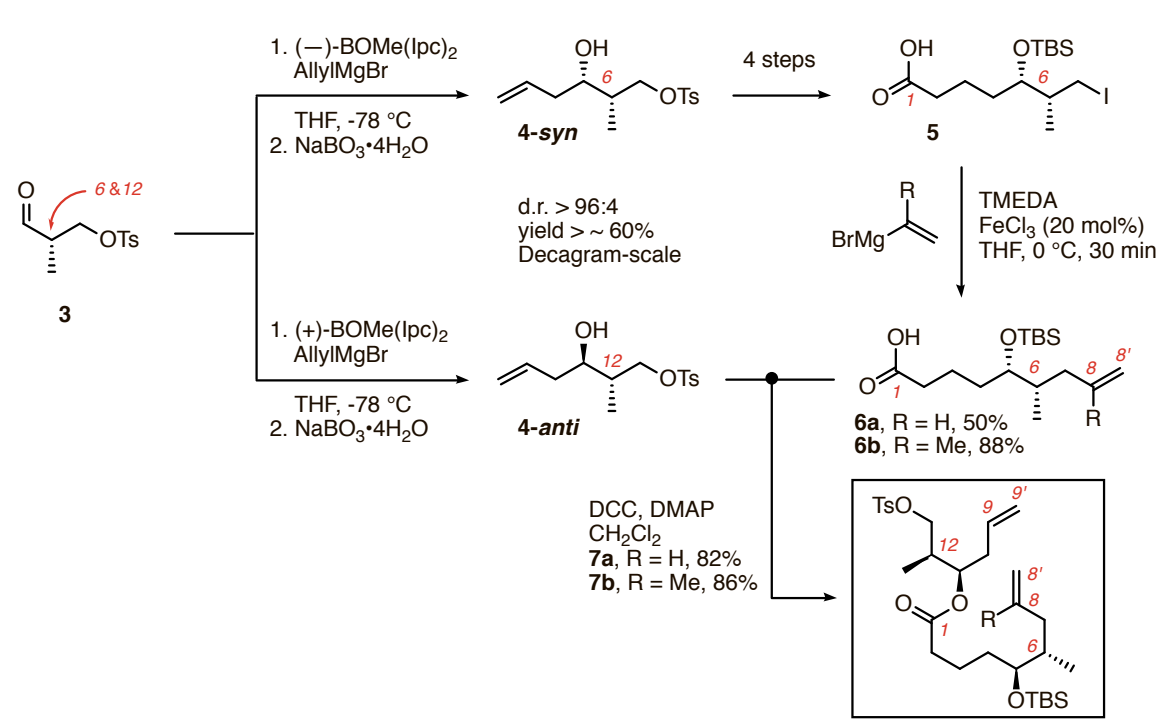

Scheme 2. First-generation synthesis of mycolactone $A / B C(1)-C(20)$ fragment.

the structural requirements of the natural product since the $\mathrm{C}(8)-\mathrm{C}(9)$ unsaturation is only 1,2-disubstituted. However, it could be further elaborated into a C8-desmethyl analogue $\mathbf{1 2}$ of the $\mathrm{C}(1)-\mathrm{C}(20)$ macrolactonic fragment.

In sharp contrast, RCM of $\mathbf{7 b}$ turned out to be very problematic and several pathways were observed such as isomerization of the $C(9)-C\left(9^{\prime}\right)$ double bond, dimerization of the more reactive terminal alkene, oligomerization and in the best cases, traces of the desired macrolactone 8b. Extensive optimization of the reaction conditions (including solvent, nature of the atmosphere, type of pre-catalyst, additives) showed that only low yields of $\mathbf{8 b}$ could be obtained using [Ru]-omega ${ }^{[23]}$ as a pre-catalyst (Scheme 3, box A2). In addition, a dramatic influence of the nature of the $C(5)$ and $C(13)$ substituents on the reactivity was noted (not shown). Alternative ring-closing metatheses strategies were also explored such as a chemoselective RCM (Scheme 3, box B1, that led exclusively to the formation of the six-membered ring even with $\mathrm{C}(15)$-iodine or $\mathrm{C}(15)-\mathrm{SnBu}_{3}$ substituents on the $\mathrm{RCM}$ precursor), a cross-metathesis (box B2, that proceeds in good yield but requires an excess of the less reactive $\mathrm{C}(1)-\mathrm{C}(8)$ fragment) and a silicon-tethered RCM (box B3, model substrates only led to low to moderate yields). Unfortunately, while this study was on-going, Altmann reported a similar strategy that met with success using a RCM precursor with a sterically less-demanding protecting group on the $\mathrm{C}(5)$ hydroxyl function, ${ }^{[24]}$ thus forcing us to revise our synthetic blueprint.

\section{Second Strategy for the Synthesis of the C(1)-C(20) Fragment of Mycolactone A/B}

In a second approach towards the $\mathrm{C}(1)-\mathrm{C}(20)$ fragment of mycolactone $\mathrm{A} / \mathrm{B}$ (Scheme 4), we envisioned that the synthesis of the $C(8)-C(9)$ trisubstituted alkene could arise from a palladium(II)-catalyzed Z-bromoallylation of a terminal alkyne, an underused reaction first reported by Kaneda in the late 1970s.[25]

Indeed, starting from the first-generation intermediate 4-syn, the primary tosylate 13 was prepared in five trivial steps. Nucleophilic substitution of the C(7)-OTs occurred smoothly with the commercially availablelithiumacetylide $\bullet$ thylenediamine complex in a DMSO/THF solvent system at $0{ }^{\circ} \mathrm{C}$. Kaneda's bromoallylation of the intermediate terminal alkyne then took place in $97 \%$ yield using allyl bromide, $\mathrm{PdBr}_{2}(\mathrm{PhCN})_{2}(5 \mathrm{~mol} \%)$ and an insoluble mineral base in THF at room temperature. Compound $\mathbf{1 4}$ was obtained as a single $Z$-stereoisomer that could be converted in two steps into diol $\mathbf{1 5}$ with excellent dia- 
stereoselectivity thanks to a cross-metathesis with 2-methyl-2-butene followed by an asymmetric dihydroxylation reaction $(89 \%$, d.r. $>97: 3)$. The latter derivative was transformed into seco-acid $\mathbf{1 6}$ in six steps, and then macrolactonized following a Yamaguchi reaction. Having in hand macrolactone 17, we next studied its one-pot hydroboration/Suzuki cross-coupling with vinyliodide 10b. Careful optimization revealed that the bottleneck of the sequence was the first step, a chemo- and diastereoselective hydroboration that should proceed with the desired stereoselectivity based on literature precedents ${ }^{[26]}$ and our own DFT minimization of macrolactone 17. ${ }^{[14]}$ This hydroboration step could only be achieved under ultra-sound irradiation of a 9-BBN dimer precursor in THF, leading to $18(12 S / 12 R=80: 20)$ after Suzuki cross-coupling. A late-stage modification of the $\mathrm{C}(8)$-position of the core structure of mycolactone could then be achieved, namely a Negishi cross-coupling with dimethylzinc that delivered $\mathbf{1 9}$ after selective deprotection of the $\mathrm{C}(5)$-silyloxy group.

Besides the synthesis of the natural $\mathrm{C}(1)-\mathrm{C}(20)$ sector of mycolactone $\mathrm{A} / \mathrm{B}$, the synthetic strategies outlined in Schemes 3 and 4 were easily diverted and led to the preparation of a library of simplified macrolactonic fragments of the exotoxin (not shown). ${ }^{[10,11,27]}$ Of special interest is the possibility to perform a late-stage modification of the $\mathrm{C}(8)$ position as exemplified in the case of the $\left[22,22,22-{ }^{2} \mathrm{H}_{3}\right]-$ mycolactone $\mathrm{A} / \mathrm{B}$, a deuterated isotopologue of the exotoxin (data not shown here). ${ }^{[15]}$ We next turn our attention to the synthesis of the southern fragment of mycolactone $\mathrm{A} / \mathrm{B}$, as discussed in the next paragraph.

\section{Synthesis of the $\mathrm{C}\left(1^{\prime}\right)-C\left(16^{\prime}\right)$ \\ Fragment of Mycolactone A/B}

Data from the Kishi, ${ }^{[17,28]}$ Altmann ${ }^{[19]}$ and Blanchard's ${ }^{[10-15]}$ groups point to the importance of the $\mathrm{C}\left(1^{\prime}\right)-\mathrm{C}\left(16^{\prime}\right)$ sector of mycolactone A/B for its biological activities. ${ }^{[1,2]}$ Considering the pharmacological importance of this fragment, it was required to develop a robust and flexible synthetic strategy that could lead to designed analogues with minimal revision of the blueprint.

The optimal route for our purpose is reported in Scheme 5 and relies on the regioselective asymmetric dihydroxylation of the conjugated trienoic acid ester 20. Diol 21 was obtained in $86 \%$ ee and was further transformed into the corresponding carbonate whose allylic position was reduced thanks to a method proposed by O'Doherty. ${ }^{[29]}$ A second asymmetric dihydroxylation targeted the more electronrich $\pi$-system of the dienoic acid ester and offered $\mathbf{2 3}$ as a single diastereomer

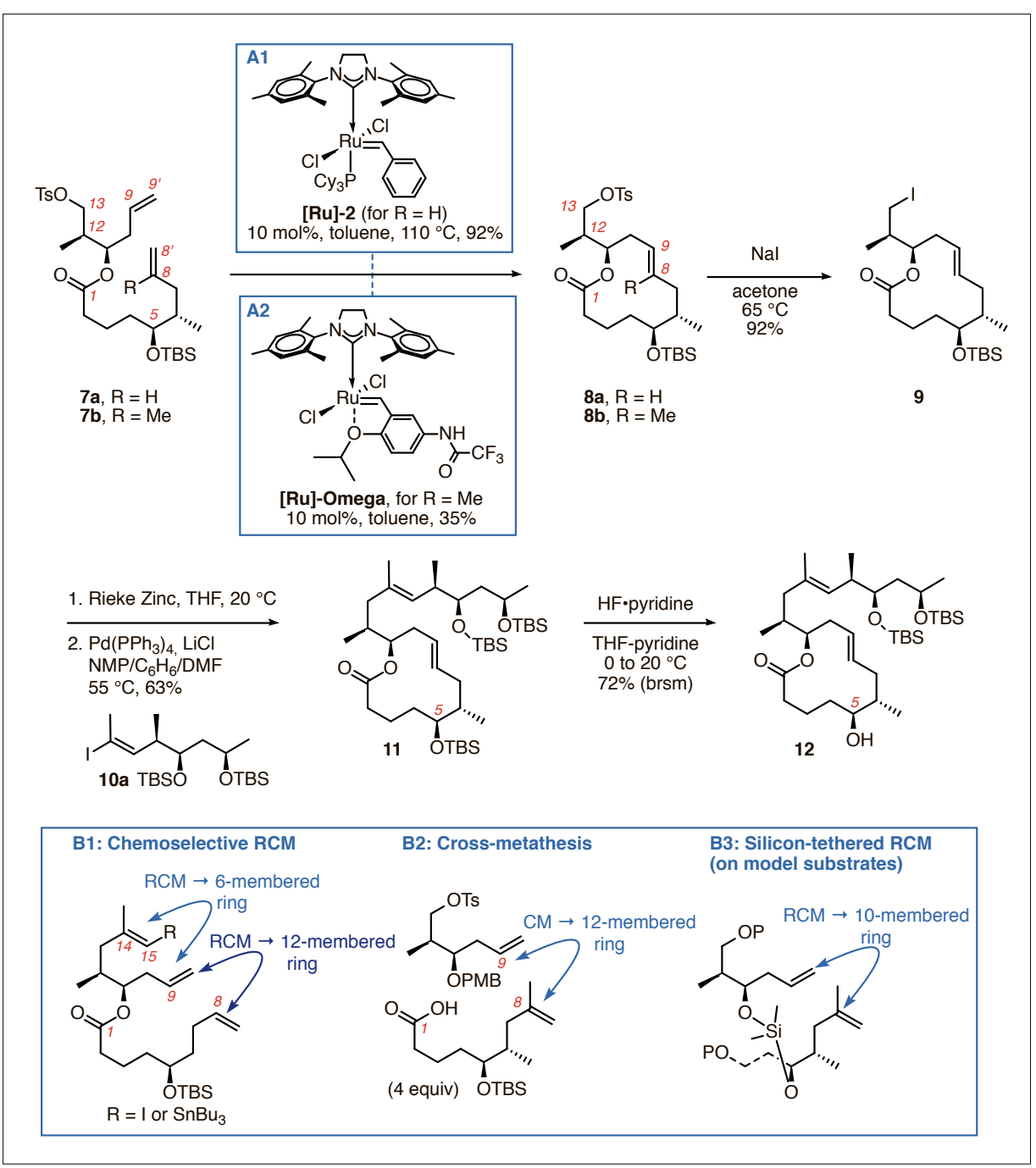

Scheme 3. Ring-closing metathesis investigations for the synthesis of mycolactone $A / B$ $C(1)-C(20)$ fragment.

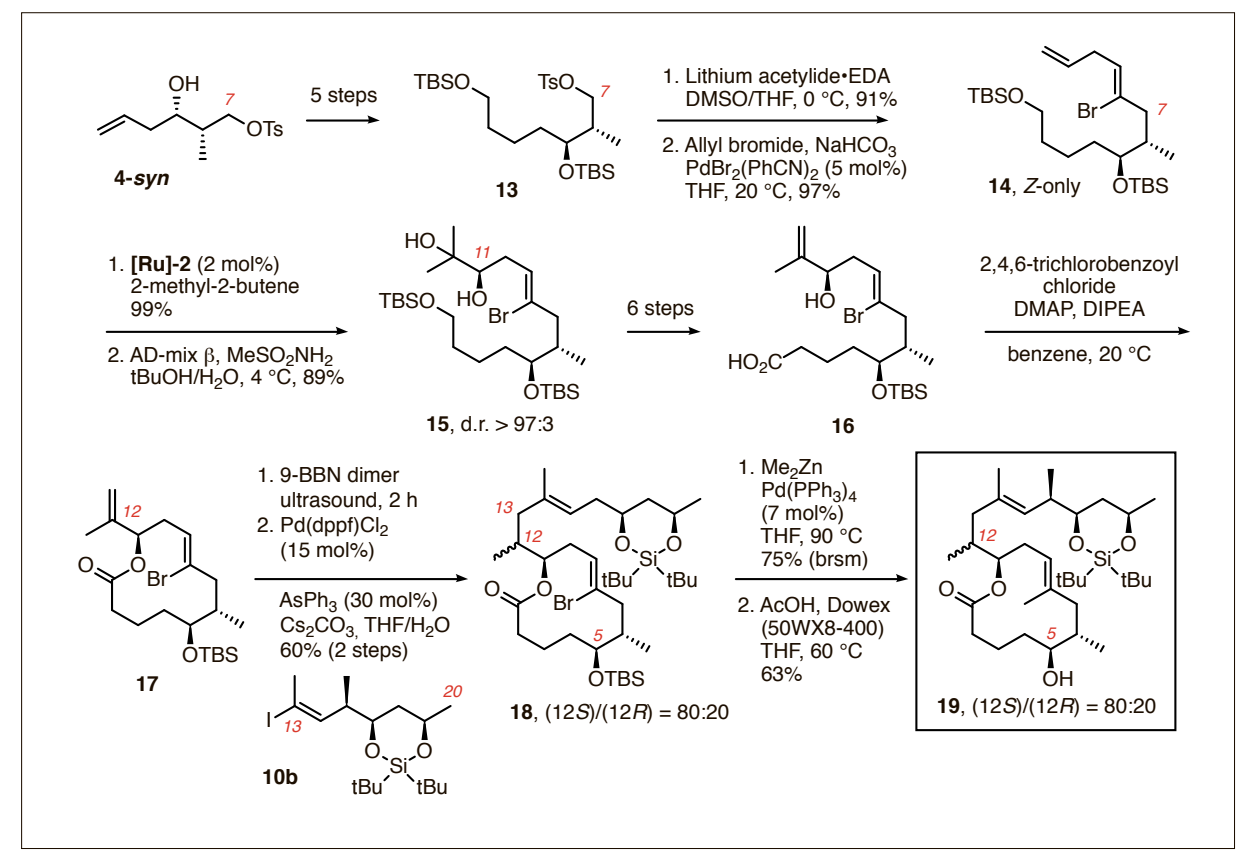

Scheme 4. Second-generation synthesis of mycolactone A/B C(1)-C(20) fragment.

in good yield. A Hodgson homologation reaction $^{[30]}$ of aldehyde $\mathbf{2 4}$ was then used to craft the dienylstannane function in $\mathbf{2 5}$, required for the Stille cross-coupling with 26. Optimization revealed that the Fürstner conditions $^{[31]}$ for the Stille reaction were 


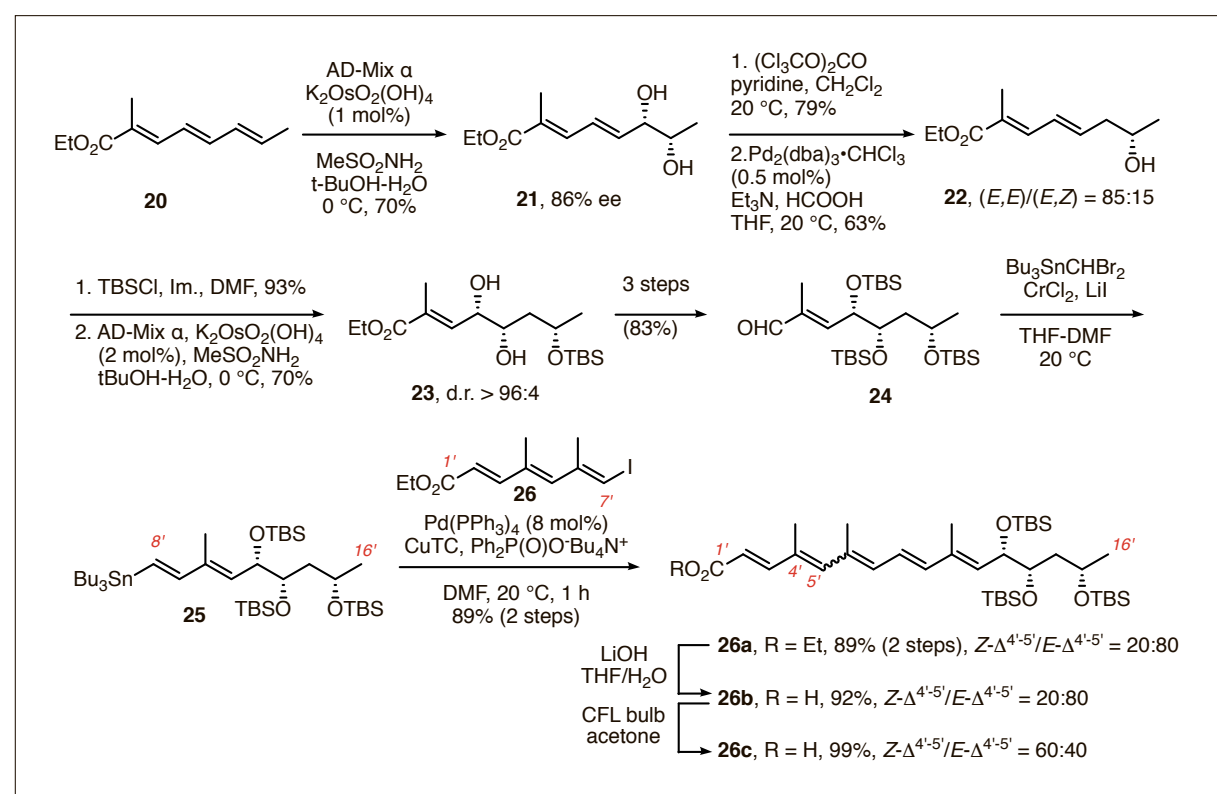

Scheme 5. Modular synthesis of mycolactone A/B C(1')-C(16') fragment.

optimal (catalytic $\operatorname{Pd}(0)$ and stoichiometric $\mathrm{Cu}(\mathrm{I})$ with a phosphinate salt as additive in DMF) and delivered the desired $\mathrm{C}\left(1^{\prime}\right)-\mathrm{C}\left(16^{\prime}\right)$ sector of mycolactone in excellent yield. Final hydrolysis with lithium hydroxide and photoisomerization of the pentaenic $\pi$-system to its thermodynamic well $\left(Z-\Delta^{4^{\prime}-5^{\prime}} / E-\Delta^{4^{\prime}-5^{\prime}}=60: 40\right)$ using a compact fluorescent light (CFL) bulb delivered the $\mathrm{C}\left(1^{\prime}\right)-\mathrm{C}\left(16^{\prime}\right)$ sector $\mathbf{2 6 c}$ of mycolactone.

The synthetic strategy outlined in Scheme 5 is modular and was exploited for the preparation of a library of southern fragments differing by the number and $a b-$ solute configurations of the $\mathrm{C}\left(12^{\prime}\right), \mathrm{C}\left(13^{\prime}\right)$ and $\mathrm{C}\left(15^{\prime}\right)$ stereogenic centers as well as by the nature of the $\mathrm{C}\left(2^{\prime}\right)-\mathrm{C}\left(11^{\prime}\right)$ polyenic system (data not shown). ${ }^{[10-15]}$

\section{Completion of the Synthesis of Mycolactone A/B}

From the above mentioned advanced intermediates, mycolactone A/B (12S/12R $=80: 20)$ and its C8-desmethyl analogue could be prepared in a few steps including an esterification reaction and a stepwise deprotection of the silyl ethers (Scheme 6).

Synthetic mycolactone A/B was identical in all aspects to the exotoxin isolated from the culture of $M$. ulcerans, including its immunosuppressive activity measured via the inhibition of the production of interleukin- 2 by phorbol 12-myristate and calcimycin-activated human $\mathrm{T}$ cells (data not shown). ${ }^{[15]}$

Besides synthetic mycolactone A/B itself and as already touched upon in the preceding sections, the different strategies briefly presented in this article allowed the preparation of a focused library of mycolactone analogues. The latter was central to the deciphering of the structure-activity relationships ${ }^{[10,11]}$ of the exotoxin as well as to the discovery of simplified analogues that are promising leads to suppress inflammatory responses. ${ }^{[13]}$

\section{Conclusions}

Exploration of the biological mechanisms behind Mycobacterium ulcerans infection is a long-term research that requires the delicate orchestration of several scientific fields, including medicine, biology and chemistry. The synthetic organic program briefly outlined in this article was initiated ten years ago and was designed in close collaboration with an Immunology group of the Pasteur Institute in Paris. Over the years, several synthetic strategies were studied in our group and led to the preparation of the largest and more diverse collection of mycolactone A/B analogues available to date, in addition to the natural product itself.

The collective efforts of synthetic Laboratories in the US, England, Switzerland and France in the field of Buruli ulcer proved central for elucidating questions raised by the unusual biology of this disease. In this regard, total synthesis is more than a sub-field of chemistry: it definitively advances the borders of chemistry while simultaneously allowing the cross-talk of different communities as clearly demonstrated in this Special Issue of CHIMIA.

\section{Acknowledgements}

The authors thank Université de HauteAlsace, Université de Strasbourg, Investissement d'Avenir (Idex Unistra), CNRS, Fondation 'Raoul Follereau', Fondation 'Pour le développement de la Chimie des Substances Naturelles et ses Applications', Académie des Sciences, GSK and Roche. In addition to the $\mathrm{PhD}$ students and post-doctoral associates whose names appear as co-authors of this article, special thanks go to the Master students that have contributed along the years to the exploration of the dead-ends and successes of this project.

Received: October 3, 2017

[1] A. C. Chany, C. Tresse, V. Casarotto, N. Blanchard, Nat. Prod. Rep. 2013, 30, 1527.

[2] M. Gehringer, K.-H. Altmann, Beilstein J. Org. Chem. 2017, 13, 1596.

[3] N. Garg, T. Luzzatto-Knaan, A. V. Melnik, A. M. Caraballo-Rodriguez, D. J. Floros, D. Petras, R. Gregor, P. C. Dorrestein, V. V. Phelan, Nat. Prod. Rep. 2017, 34, 194.

[4] P. Maccallum, J. C. Tolhurst, G. Buckle, H. A Sissons, J. Pathol. Bacteriol. 1948, 60, 93.

[5] F. S. Sarfo, R. Phillips, M. Wansbrough-Jones, R. E. Simmonds, Cell Microbiol. 2016, 18, 17.

[6] L. Guenin-Macé, R. Oldenburg, F. Chretien, C. Demangel, Cell Mol. Life Sci. 2014, 71, 2443

[7] H. Hong, C. Demangel, S. J. Pidot, P. F. Leadlay, T. Stinear, Nat. Prod. Rep. 2008, 25, 447.

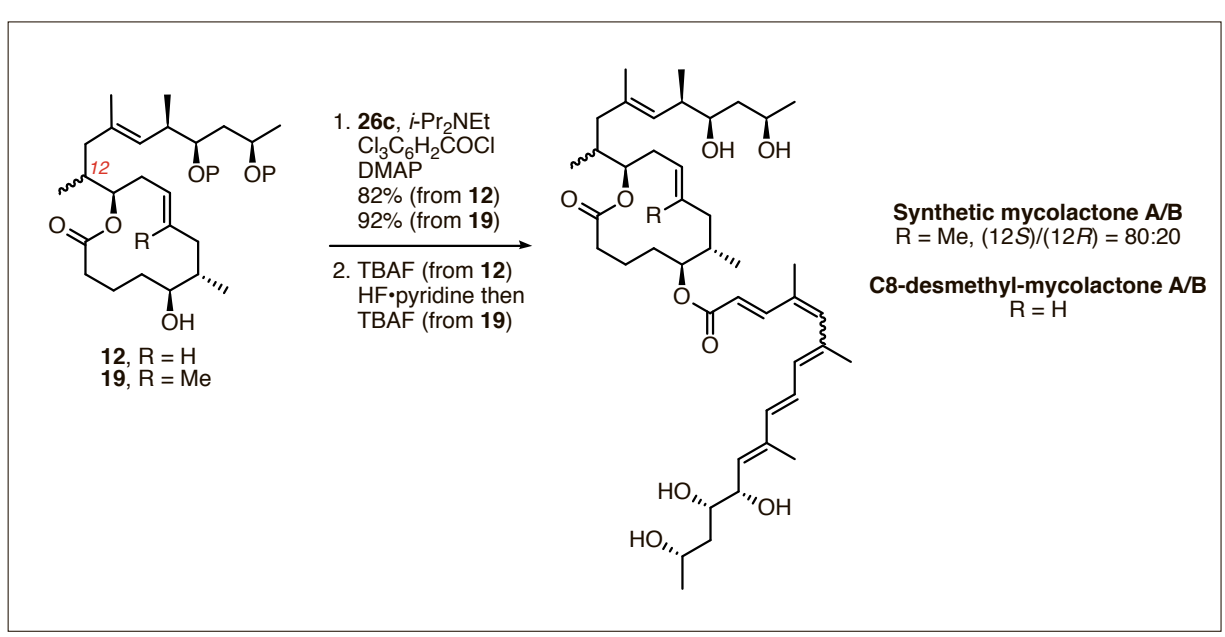

Scheme 6. Completion of the total synthesis of mycolactone A/B. 
[8] E. Marion, O.-R. Song, T. Christophe, J. Babonneau, D. Fenistein, J. Eyer, F. Letournel, D. Henrion, N. Clere, V. Paille, Nathalie C. Guérineau, J.-P. Saint André, P. Gersbach, K.-H. Altmann, Timothy P. Stinear, Y. Comoglio, G. Sandoz, L. Preisser, Y. Delneste, E. Yeramian, L. Marsollier, P. Brodin, Cell 2014, 157, 1565.

[9] K. M. George, D. Chatterjee, G. Gunawardana, D. Welty, J. Hayman, R. Lee, P. L. C. Small, Science 1999, 283, 854.

[10] A.-C. Chany, V. Casarotto, M. Schmitt, C. Tarnus, L. Guenin-Macé, C. Demangel, O. Mirguet, J. Eustache, N. Blanchard, Chem. Eur. J. 2011, 17, 14413.

[11] A.-C. Chany, R. Veyron-Churlet, C. Tresse, V. Mayau, V. Casarotto, F. Le Chevalier, L. Guenin-Macé, C. Demangel, N. Blanchard, J. Med. Chem. 2014, 57, 7382.

[12] N. Blanchard, A.-C. Chany, C. Tresse, V. Casarotto, L. Bréthous, S. Saint-Auret, Strategies and Tactics in Organic Synthesis 2015, 11, 85 .

[13] L. Guenin-Macé, L. Baron, A.-C. Chany, C. Tresse, S. Saint-Auret, F. Jönsson, F. Le Chevalier, P. Bruhns, G. Bismuth, S. HidalgoLucas, J.-F. Bisson, N. Blanchard, C. Demangel, Science Trans. Med. 2015, 7, 289ra85.
[14] S. Saint-Auret, H. Abdelkafi, D. Le Nouen, P. Bisseret, N. Blanchard, Org. Chem. Front. 2017, DOI: 10.1039/C7QO00608J.

[15] S. Saint-Auret, H. Abdelkafi, D. Le Nouen, L. Guenin-Macé, C. Demangel, P. Bisseret, N. Blanchard, Org. Biomol. Chem. 2017, 15, 7518

[16] S. Fidanze, F. B. Song, M. Szlosek-Pinaud, P. L. C. Small, Y. Kishi, J. Am. Chem. Soc. 2001, 123, 10117.

[17] Y. Kishi, Proc. Natl. Acad. Sci. U.S.A. 2011, 108, 6703 .

[18] G. W. Wang, N. Yin, E. Negishi, Chem. Eur. J. 2011, 17, 4118 .

[19] P. Gersbach, A. Jantsch, F. Feyen, N. Scherr, J.P. Dangy, G. Pluschke, K.-H. Altmann, Chem Eur. J. 2011, 17, 13017.

[20] C. A. Brown, V. K. Aggarwal, Chem. Eur. J. 2015, 21, 13900.

[21] J. Cossy, C. Meyer, S. Arséniyadis, 'Metathesis in Natural Product Synthesis: Strategies, Substrates and Catalysts', Wiley-VCH, Weinheim, 2010.

[22] A. Guérinot, S. Reymond, J. Cossy, Angew. Chem. Int. Ed. 2007, 46, 6521.

[23] a) H. Clavier, F. Caijo, E. Borré, D. Rix, F. Boeda, S. P. Nolan, M. Mauduit, Eur. J. Org.
Chem. 2009, 4254; b) For a recent application, see : C. Bressy, J. Merad, P. Borkar, F Caijo, J.-M. Pons, J.-L. Parrain, O. Chuzel, Angew. Chem. Int. Ed. 2017, DOI: 10.1002/ anie. 201709844.

[24] F. Feyen, A. Jantsch, K. H. Altmann, Synlett 2007, 415.

[25] K. Kaneda, T. Uchiyama, Y. Fujiwara, T. Imanaka, S. Teranishi, J. Org. Chem. 1979, 44, 55.

[26] W. C. Still, J. C. Barrish, J. Am. Chem. Soc. 1983, 105, 2487.

[27] C. Demangel, N. Blanchard, G. Bismuth, J. Eustache, V. Casarotto, A. C. Chany, 2013. EP594561 A1.

[28] a) X. Li, V. S. Babu, Y. Kishi, Tetrahedron Lett. 2015, 56, 3220; b) V. S. Babu, Y. Zhou, Y. Kishi, Bioorg. Med. Chem. Lett. 2017, 27, 1274.

[29] T. J. Hunter, G. A. O’Doherty, Org. Lett. 2001, 3, 1049.

[30] D. M. Hodgson, L. T. Boulton, G. N. Maw, Tetrahedron 1995, 51, 3713.

[31] A. Fürstner, J.-A. Funel, M. Tremblay, L. C. Bouchez, C. Nevado, M. Waser, J. Ackerstaff, C. C. Stimson, Chem. Commun. 2008, 2873. 